(2) Open Access Full Text Article

REVIEW

\title{
Latanoprostene bunod ophthalmic solution $0.024 \%$ in the treatment of open-angle glaucoma: design, development, and place in therapy
}

This article was published in the following Dove Press journal:

Clinical Ophthalmology

\author{
Victoria M Addis \\ Eydie Miller-Ellis \\ Division of Glaucoma, Scheie Eye \\ Institute, University of Pennsylvania, \\ Philadelphia, PA, USA
}

Correspondence: Victoria M Addis Division of Glaucoma, Scheie Eye Institute, University of Pennsylvania, 5I N. 39th St, Philadelphia, PA 19104, USA

Tel + I 2156628715

Fax +I 2152438825

Email miller@uphs.upenn.edu

\begin{abstract}
Latanoprostene bunod (LBN) $0.024 \%$, a modified prostaglandin analog, was approved on November 2, 2017, for the reduction of IOP in patients with open-angle glaucoma (OAG) or ocular hypertension (OHT). LBN works by combining the IOP-lowering effects of the prostaglandin analogs (through the uveoscleral pathway) with nitric oxide-induced relaxation of the trabecular meshwork and Schlemm's canal. Nitric oxide-induced relaxation of the trabecular meshwork and Schlemm's canal leads to increased outflow through the trabecular meshwork and thus lowering of IOP. LBN has now been shown in multiple clinical studies to be effective and safe. In this article, we summarize the clinical trials that led to LBN's approval as well as the comparative studies that have been done to evaluate the efficacy of this drug as compared to other US Food and Drug Administration (FDA)-approved therapies for OAG and OHT. We then review the side effects of treatment that were seen in each of these studies. Finally, we will attempt to discuss the place of this drug in therapy for patients with OAG.
\end{abstract}

Keywords: latanoprostene bunod, open-angle glaucoma, ocular hypertension, modified prostaglandin analog, nitric oxide, treatment-associated adverse event

\section{Background}

More than 2 million people in the United States are estimated to be affected by openangle glaucoma (OAG), a number that is expected to increase to $>3$ million by 2020 , due to the rapidly aging population. ${ }^{1}$ Patients with $\mathrm{OAG}$ suffer progressive deterioration of the optic nerve which results in characteristic visual field loss. ${ }^{2}$ Glaucoma is the second most common cause of blindness worldwide, and vision loss from glaucoma is irreversible. Reduction of IOP remains the only modifiable risk factor in the treatment of glaucoma, ${ }^{3}$ and patients who achieve target IOP reduction have a lower risk of disease progression. ${ }^{4}$ In the Early Manifest Glaucoma Trial (EMGT), treated patients had half the progression risk of control patients and the magnitude of initial IOP reduction significantly influenced outcome. It was estimated that among patients in the EMGT every $1 \mathrm{~mm} \mathrm{Hg}$ of IOP lowering resulted in an estimated $10 \%-20 \%$ risk reduction in visual field loss. ${ }^{5,6}$

Pharmacological therapies, in the form of topical eye drops, remain the most common first-line intervention for IOP reduction. Laser and surgical therapies, including minimally invasive surgical techniques, are additional options, and there have been multiple new devices recently approved for the treatment of OAG. Currently available classes of medication include the following: prostaglandin analogs and the newer modified prostaglandin analogs, beta-adrenergic antagonists, alpha-2-adrenergic agonists, 
carbonic anhydrase inhibitors, cholinergic agonists, and, most recently, rho-kinase inhibitors. ${ }^{7}$ Latanoprostene bunod (LBN) ophthalmic solution $0.024 \%$ (Vyzulta ${ }^{\mathrm{TM}}$, Valeant Pharmaceuticals, Bridgewater, NJ, USA), the first modified prostaglandin analog, was approved on November $2,2017,{ }^{8}$ for the reduction of IOP in patients with OAG or ocular hypertension (OHT).

In this review, we will first provide an overview of the modified prostaglandin analogs, including a short summary of their mechanism of action. Expert reviews detailing the pharmacological properties of LBN have been published previously ${ }^{9,10}$ and will thus not be repeated here. Rather, we will concentrate on the clinical studies that led to LBN's approval as well as the comparative studies to date that have been done to study the efficacy of this drug as compared to other FDA-approved therapies for glaucoma (Table 1). We will review side effects of treatment (Table 2) as well as outline the place of this drug in therapy for patients with OAG. We will review the many barriers to glaucoma medication adherence and discuss how LBN may ultimately improve patient adherence and compliance to glaucoma therapy.

\section{Mechanism of action}

IOP is determined by the balance between aqueous humor production by the ciliary body and elimination through the trabecular meshwork (the conventional outflow system) and the uveoscleral tract (the nonconventional outflow system). While other classes of IOP-lowering therapy have primarily one mechanism of action, the modified prostaglandin analogs have a dual mechanism of action. They combine the IOP-lowering effects of prostaglandin analogs using the uveoscleral outflow system, with nitric oxide-induced relaxation of the trabecular meshwork and Schlemm's canal. This nitric oxide-induced relaxation of the trabecular meshwork and Schlemm's canal thereby increases outflow through the trabecular meshwork outflow system. ${ }^{11}$

Upon topical administration, LBN $0.024 \%$, the first FDAapproved drug in the category of modified prostaglandin analogs, becomes metabolized by esterases into latanoprost acid, an F2 $\alpha$ prostaglandin analog, and butanediol mononitrate. Nitric oxide is then released from butanediol mononitrate with an inactive metabolite, 1,4-butanediol. ${ }^{10,14}$ latanoprost acid lowers IOP by increasing outflow through the nonconventional uveoscleral outflow system, ${ }^{12}$ while butanediol mononitrate acts as a nitric oxide donor which results in increased trabecular meshwork outflow by relaxation of cells in the trabecular meshwork and Schlemm's canal. ${ }^{13}$ Lowering of IOP from Latanoprostene has been seen in glaucomatous dogs as well as primates with OHT. ${ }^{13,14}$ In Prostaglandin
F-receptor knockout mice (a mouse model that is insensitive to the actions of the prostaglandin analogs), as well as in rabbits ${ }^{13}$ (who are believed not to have the receptor for prostaglandin analogs), LBN also reduced IOP,${ }^{15}$ suggesting the additional IOP-lowering effect of nitric oxide.

\section{Efficacy and comparative studies Phase I}

KRONUS, a Phase I, single-arm, single-center, open-label clinical study, was designed to evaluate the effectiveness of LBN $0.024 \%$ at IOP lowering in 24 healthy Japanese male volunteers. The mean age of the study subjects was 26.8 years with an SD of 6.3 years, and the mean baseline IOP in these subjects was $13.6 \mathrm{~mm} \mathrm{Hg}$ with an SD of $1.3 \mathrm{~mm} \mathrm{Hg}$. After establishing a baseline diurnal and nocturnal IOP in each of these individuals, subjects instilled one drop of LBN $0.024 \%$ in both eyes at $8 \mathrm{pm}$ for a total of 14 days. The absolute as well as the change in IOP from baseline was then reassessed in each of these study subjects on day 14 at each of the same previously measured time points. IOP was found to be reduced at all assessed time points $(P<0.001)$. The mean 24-hour reduction in IOP was $27 \%$ or $3.6 \mathrm{~mm} \mathrm{Hg}$ (with an $\mathrm{SD}$ of $0.8 \mathrm{~mm} \mathrm{Hg}) .{ }^{16} \mathrm{KRONUS}$ and the below studies have been summarized in Table 1.

\section{Phase II}

The VOYAGER study was a Phase II randomized, investigator-masked, parallel group study designed to determine the optimum effective concentration as well as tolerability of latanoprostene. This study served as a controlled comparison of LBN and latanoprost $0.005 \%$ in patients with OAG or OHT. Subjects were randomized to one of five groups with varying concentrations of latanoprostene ranging from $0.006 \%$ to $0.040 \%(0.006 \%, 0.012 \%, 0.024 \%$, and $0.040 \%$ ), with one of the groups receiving latanoprost $0.005 \%$. Four hundred thirteen patients were randomized, and 396 patients completed this study over a 28-day period. There was a significant reduction in mean diurnal IOP from baseline (at all follow up visits) with each treatment group, though among the groups treated with LBN, the IOP reductions were dose dependent and seemed to plateau with the $0.024 \%-0.040 \%$ dose. The maximal IOP-lowering effect of latanoprost was previously reported at a concentration of $0.005 \% .{ }^{17}$ This suggests that LBN $0.024 \%$ 's additional IOP lowering over latanoprost $0.005 \%$ is not due to any additional latanoprost acid released by LBN $0.024 \%$ over latanoprost $0.005 \% .^{9}$ The absolute change in mean baseline diurnal IOP was the primary endpoint of the study, with LBN 0.024\% found to be the lowest concentration to achieve the largest 


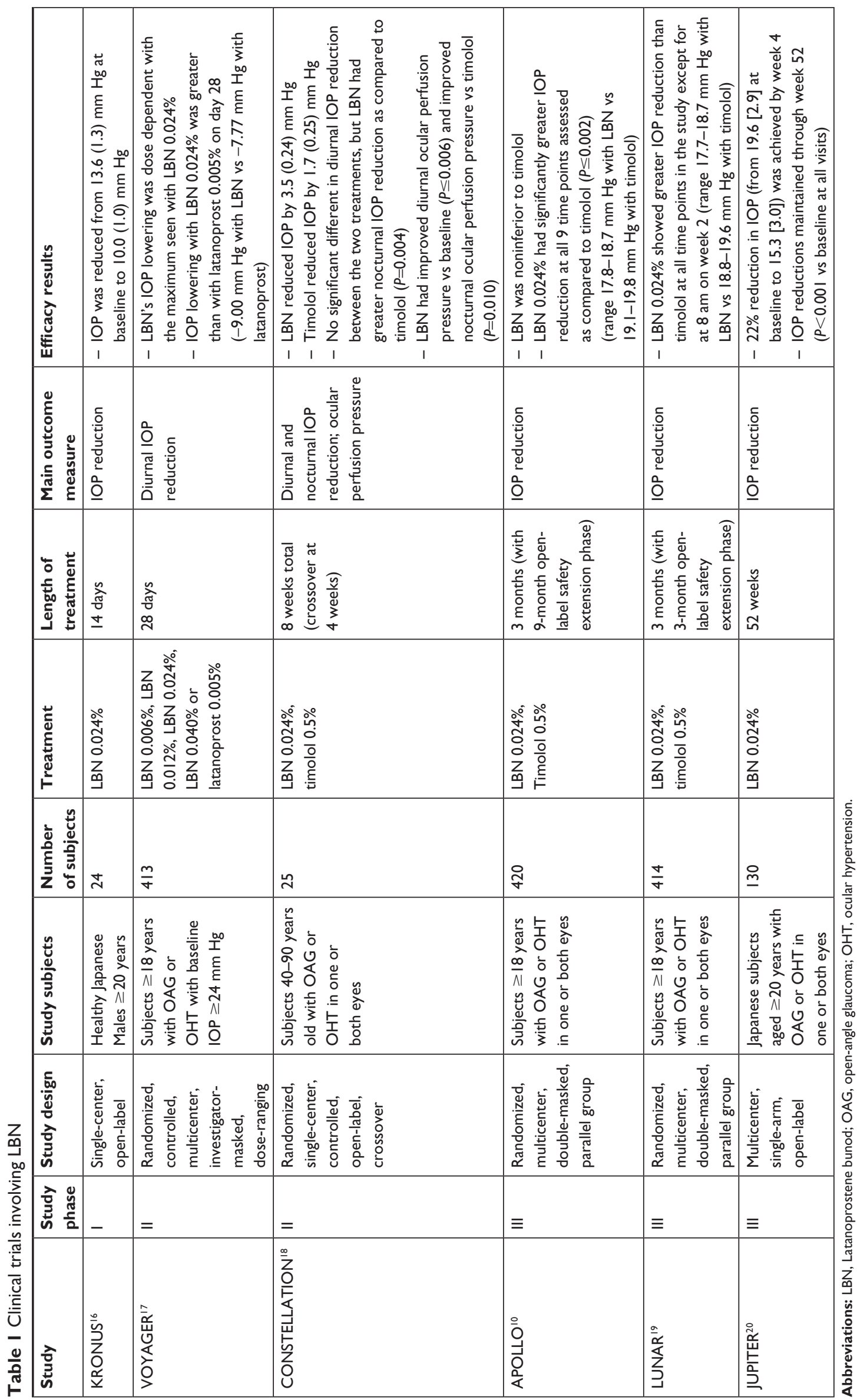


Table 2 Safety and tolerability of LBN $0.024 \%$

\begin{tabular}{|c|c|c|c|c|}
\hline $\begin{array}{l}\text { Study (number of subjects } \\
\text { treated with LBN } 0.024 \% \text { ) }\end{array}$ & Ocular TEAEs & $\begin{array}{l}\text { Number of } \\
\text { subjects (\%) }\end{array}$ & $\begin{array}{l}\text { Nonocular TEAEs potentially } \\
\text { related to treatment } \\
\text { (number of subjects) }\end{array}$ & $\begin{array}{l}\text { Study } \\
\text { discontinuations } \\
\text { (number of subjects) }\end{array}$ \\
\hline KRONUS ${ }^{16}(24)$ & $\begin{array}{l}\text { Conjunctival hyperemia } \\
\text { Punctate keratitis } \\
\text { Unspecified conjunctival disorder } \\
\text { Eye pain } \\
\text { Reduced visual acuity }\end{array}$ & $\begin{array}{l}\text { I2 (50) } \\
\text { I3 (54) } \\
\text { I ( } 4) \\
\text { I (4) } \\
\text { I (4) }\end{array}$ & $\begin{array}{l}\text { None of the nonocular TEAEs } \\
\text { were considered related to the } \\
\text { study drug }\end{array}$ & None \\
\hline $\begin{array}{l}\text { VOYAGER }{ }^{17}(83) \\
* * \text { Data included from LBN } \\
0.024 \% \text { group only }\end{array}$ & $\begin{array}{l}\text { Instillation site pain } \\
\text { Conjunctival hyperemia } \\
\text { Punctate keratitis } \\
\text { Ocular hyperemia } \\
\text { Eye irritation } \\
\text { Dry eye } \\
\text { Photophobia }\end{array}$ & $\begin{array}{l}10(12) \\
4(4.8) \\
2(2.4) \\
2(2.4) \\
3(3.6) \\
2(2.4) \\
2(2.4)\end{array}$ & Headache (I) & I \\
\hline CONSTELLATION $^{18}(25)$ & $\begin{array}{l}\text { Punctate keratitis } \\
\text { Instillation site erythema }\end{array}$ & $\begin{array}{l}\text { I (4) } \\
\text { I (4) }\end{array}$ & $\begin{array}{l}\text { Nausea (I) } \\
\text { Hyperhidrosis (I) }\end{array}$ & 4 \\
\hline $\operatorname{APOLLO}^{10}(283)$ & $\begin{array}{l}\text { Eye irritation } \\
\text { Conjunctival hyperemia } \\
\text { Eye pain } \\
\text { Dry eye } \\
\text { Foreign body sensation in eyes } \\
\text { Instillation site pain }\end{array}$ & $\begin{array}{l}3 \mathrm{I}(\mathrm{II}) \\
\mathrm{II}(3.9) \\
8(2.8) \\
3(\mathrm{I} . \mathrm{I}) \\
3(\mathrm{I} . \mathrm{I}) \\
3(\mathrm{I} . \mathrm{I})\end{array}$ & $\begin{array}{l}\text { Headache }(2) \\
\text { Fatigue (I) } \\
\text { Sinus congestion (I) } \\
\text { Hair disorder (I) }\end{array}$ & 2 \\
\hline LUNAR $^{19}$ (277) & $\begin{array}{l}\text { Conjunctival hyperemia } \\
\text { Eye irritation } \\
\text { Eye pain } \\
\text { Ocular hyperemia } \\
\text { Vision blurred } \\
\text { Eye pruritus } \\
\text { Dry eye } \\
\text { Punctate keratitis } \\
\text { Foreign body sensation in eyes } \\
\text { Instillation site pain }\end{array}$ & $\begin{array}{l}25(9) \\
20(7.2) \\
16(5.8) \\
7(2.5) \\
5(1.8) \\
4(1.4) \\
3(1.1) \\
3(1.1) \\
3(1.1) \\
4(1.4)\end{array}$ & $\begin{array}{l}\text { Madarosis (I) } \\
\text { Chest discomfort (I) } \\
\text { Dysgeusia (I) } \\
\text { Headache (I) } \\
\text { Insomnia (I) } \\
\text { Dyspnea (I) }\end{array}$ & 4 \\
\hline JUPITER ${ }^{20}(130)$ & $\begin{array}{l}\text { Conjunctival hyperemia } \\
\text { Growth of eyelashes } \\
\text { Eye irritation } \\
\text { Eye pain } \\
\text { Iris hyperpigmentation } \\
\text { Blepharal pigmentation } \\
\text { Blepharitis } \\
\text { Eye pruritus } \\
\text { Asthenopia } \\
\text { Conjunctival hemorrhage } \\
\text { Punctate keratitis } \\
\text { Trichiasis } \\
\text { Cataract } \\
\text { Hordeolum } \\
\text { Foreign body sensation in eyes } \\
\text { Visual impairment } \\
\text { Vitreous floaters }\end{array}$ & $\begin{array}{l}23(17.7) \\
21(16.2) \\
15(11.5) \\
13(10) \\
5(3.8) \\
4(3.1) \\
3(2.3) \\
3(2.3) \\
3(2.3) \\
2(1.5) \\
3(2.3) \\
3(2.3) \\
\text { I }(0.8) \\
1(0.8) \\
2(1.5) \\
\text { I }(0.8) \\
\text { I }(0.8)\end{array}$ & $\begin{array}{l}\text { None of the nonocular TEAEs } \\
\text { were considered related to the } \\
\text { study drug }\end{array}$ & 4 \\
\hline
\end{tabular}

Note: Data has only been included from the LBN $0.024 \%$ group since the table is discussing the safety and tolerability of LBN $0.024 \%$. Abbreviations: LBN, Latanoprostene bunod; TEAE, treatment-emergent adverse events.

reduction in IOP as compared to latanoprost $0.005 \%$. IOP in subjects treated with LBN $0.024 \%$ was found to be lower than those treated with latanoprost $0.005 \%$ at days 7,14 , and 28 , which suggested that the nitric oxide component of the medication provided additional IOP lowering. ${ }^{18}$
CONSTELLATION was a Phase II prospective, openlabel randomized crossover trial designed to compare the efficacy of LBN $0.024 \%$ with timolol $0.5 \%$ in lowering IOP both during diurnal and nocturnal hours. Twenty-five patients aged 43-82 years old with early OAG (4 patients) or 
OHT (21 patients) had their baseline IOP and blood pressure checked in a sleep laboratory both in the sitting and supine position every 2 hours during the 16-hour diurnal (wake) period and in the supine position every 2 hours during the 8 -hour nocturnal (sleep) period. These subjects were then randomly assigned to receive LBN $0.024 \%$ at 8 pm or timolol $0.5 \%$ at 8 am and $8 \mathrm{pm}$ in both eyes, and the same IOP and blood pressure readings were repeated after a 4-week period. Subjects were then switched to the other treatment for the next 4-week period, and the measurements were repeated again. Twenty-one individuals completed the study. Both treatments were found to significantly lower IOP during both the diurnal and nocturnal periods as compared to baseline $(P<0.001)$. No significant difference between the treatments was found in terms of overall diurnal IOP reductions; however, LBN $0.024 \%$ was found to have greater IOP reduction and an increase in ocular perfusion pressure over timolol $0.5 \%$ during the nocturnal period $(P=0.10) .{ }^{19}$

\section{Phase III}

APOLLO was a Phase III, randomized, controlled, multicenter, double-masked, parallel-group study designed to compare the diurnal IOP-lowering effect of LBN $0.024 \%$ vs timolol $0.5 \%$ in subjects with OAG or OHT. In this study, 420 individuals $\geq 18$ years of age with a diagnosis of either $\mathrm{OAG}$ or OHT in one or both eyes were randomized (2:1) to receive a 3 -month regimen of either LBN $0.024 \%$ nightly or timolol $0.5 \%$ twice a day, with 387 subjects completing the study. IOP was checked at $8 \mathrm{am}, 12 \mathrm{pm}$, and $4 \mathrm{pm}$ at weeks 2 , 6 , and month 3 after beginning therapy. LBN $0.024 \%$ was found to have significantly greater IOP reduction at all 9 time points assessed as compared to timolol $0.5 \%(P \leq 0.002)$ (the primary efficacy end point), and more patients treated with LBN $0.024 \%$ achieved $\geq 25 \%$ reduction in IOP and a mean IOP $\leq 18$ during the course of treatment (secondary efficacy end points). Among patients in the LBN $0.024 \%$ group, $34.9 \%$ achieved $\geq 25 \%$ reduction in IOP as compared to $19.5 \%$ of patients in the timolol $0.5 \%$ group $(P=0.001)$. In addition, $22.9 \%$ of patients in the LBN $0.024 \%$ had a mean IOP $\leq 18$ compared to $11.3 \%$ of patients in the timolol $0.5 \%$ group $(P=0.005) .^{10}$

The LUNAR study was a prospective, randomized, double-masked, parallel-group, noninferiority trial. Similar to APOLLO, the LUNAR study was designed to compare the IOP-lowering effect of LBN $0.024 \%$ with timolol $0.5 \%$ in individual with OAG or OHT. Adults with OAG or OHT were enrolled from 46 clinical sites in the United States and the European Union, with 387 subjects completing the study. Subjects were randomized 2:1 to LBN $0.024 \%$ instilled nightly with vehicle in the morning or timolol $0.5 \%$ twice a day for 3 months. IOP was checked at $8 \mathrm{am}, 12 \mathrm{pm}$, and 4 pm at week 2 , week 6 , and month 3 . In addition to being noninferior to timolol therapy, LBN $0.024 \%$ showed greater IOP reduction than timolol at all time points in the study except for at 8 am on week 2 . The percentage of patients with $\geq 25 \%$ reduction in IOP from baseline was higher in the LBN group as compared to the timolol group (31.0\% vs $18.5 \%, P=0.007)$ and a higher percentage of subjects in the LBN group than in the timolol group had their IOP reduced to $\leq 18 \mathrm{~mm} \mathrm{Hg}(17.7 \%$ vs $11.1 \%)$ though this was not significantly significant $(P=0.084) .{ }^{19}$

In a pooled analysis of the APOLLO and LUNAR studies, LBN $0.024 \%$ provided greater IOP lowering compared to timolol $0.5 \%$ at 3 months of therapy and remained effective during the open-label extension phases of both studies. Lowered IOP was maintained in both studies for as long as 12 months after the initiation of treatment. ${ }^{20}$

The JUPITER study was a single-arm, multicenter, openlabel clinical study that evaluated the long-term safety and IOP-lowering efficacy of LBN $0.024 \%$ in Japanese subjects with OAG or OHT over 1 year of treatment. Subjects aged 20 years and older (mean age 62.5 years) with a diagnosis of OAG or OHT used one drop of LBN $0.024 \%$ nightly in both eyes for 52 weeks. The study enrolled 130 subjects, with $121(93.1 \%)$ completing the trial. Individuals were assessed every 4 weeks. Mean (SD) baseline IOP at the beginning of the study was $19.6(2.9) \mathrm{mm} \mathrm{Hg}$ in study eyes (range 15.0-30 $\mathrm{mm} \mathrm{Hg}$ ) and 18.7 (2.6) $\mathrm{mm} \mathrm{Hg}$ in fellow eyes (range $14.5-27.0 \mathrm{~mm} \mathrm{Hg}$ ). A 22\% reduction in IOP to 15.3 (3.0) $\mathrm{mm} \mathrm{Hg}$ was achieved by week 4 in study eyes and a $19.5 \%$ reduction in IOP to $15.0(2.8) \mathrm{mm} \mathrm{Hg}$ in fellow eyes. This percent IOP reduction was maintained or increased through the end of the 52-week study $(P<0.001$ vs baseline at all visits) with study eyes achieving $26 \%$ IOP reduction to 14.4 (2.7) $\mathrm{mm} \mathrm{Hg}$ by 52 weeks. ${ }^{21}$

\section{Safety and tolerability}

Given that glaucoma is a chronic, currently incurable disease, the importance of long-term, safe and tolerable medications cannot be overestimated. Both local and systemic side effects of available medications are well known, including adverse skin reactions. ${ }^{22}$ Ocular surface toxicity from preservatives such as benzalkonium chloride, present in many eye drops, has been well studied, ${ }^{23}$ as has the benefits of preservativefree medications. ${ }^{24}$ Some experts have even argued that all patients should receive preservative-free medications. ${ }^{25}$ Treatment-emergent adverse events (TEAEs), associated with LBN therapy, have been reported in nearly all clinical 
trials of this medication to date. Overall, LBN $0.024 \%$ has been shown to be a well-tolerated medication with a relatively mild side-effect profile. Clinical trials reporting TEAEs are discussed below and listed in Table 2.

In the KRONUS study, 21/24 subjects (87.5\%) experienced at least one TEAE. The most common adverse events were conjunctival hyperemia (experienced in 12/24 study eyes and reported to be mild in all cases) and punctate keratitis (experienced in 13/24 study eyes). An unspecified conjunctival disorder, eye pain, and reduced visual acuity were each reported by one study subject, though all enrolled subjects completed the study. Mild upper respiratory inflammation which was thought unrelated to study treatment was reported by one study subject. ${ }^{16}$

LBN was also well tolerated in the VOYAGER study, though there was a numerically higher incidence of ocular side effects reported in the groups randomized to LBN as compared with the latanoprost group. The incidence of hyperemia was similar between the two groups. Instillation site pain was reported by $14.6 \%, 16.7 \%, 12.0 \%$, and $17.3 \%$ of subjects in the LBN $0.006 \%, 0.012 \%, 0.024 \%$, and $0.040 \%$ groups, respectively, vs $6.1 \%$ of subjects in the latanoprost group. Ocular hyperemia was reported by $1.2 \%, 6.0 \%, 2.4 \%$, and $4.9 \%$ of subjects in the LBN $0.006 \%, 0.012 \%, 0.024 \%$, and $0.040 \%$ groups, respectively, vs $8.5 \%$ in the latanoprost group, whereas conjunctival hyperemia was reported for $1.2 \%, 3.6 \%, 4.8 \%$, and $3.7 \%$ of subjects in the LBN $0.006 \%$, $0.012 \%, 0.024 \%$, and $0.040 \%$ groups, respectively. Serious nonocular TEAEs were rare and considered unrelated to the study drug. Only headache was reported more than once (one individual each in the latanoprost, LBN $0.012 \%$ and LBN $0.024 \%$ groups) and thought to be potentially related to topical therapy. Of the 413 enrolled subjects, 6 discontinued from the study due to a TEAE; discontinuation reasons included asthma ( $\mathrm{n}=1$, LBN $0.006 \%)$, migraine with aura $(\mathrm{n}=1, \mathrm{LBN} 0.006 \%)$, instillation site pain ( $\mathrm{n}=1$, LBN $0.006 \%$, $\mathrm{n}=1, \mathrm{LBN} 0.012 \%)$, instillation site erythema $(\mathrm{n}=1, \mathrm{LBN}$ $0.024 \%$ ), and myocardial infarction ( $\mathrm{n}=1$, latanoprost). ${ }^{17}$

In the APOLLO study, both LBN $0.024 \%$ and timolol $0.5 \%$ were associated with a comparable percentage of both ocular and nonocular adverse events. Adverse events reported in $\geq 1 \%$ of eyes in both groups included eye irritation, conjunctival hyperemia, eye pain, dry eye, foreign body sensation, and instillation site pain. Subjects in the LBN $0.024 \%$ had a higher percentage of moderate to severe hyperemia at all time points compared to the timolol $0.5 \%$ group. Two subjects in the LBN $0.024 \%$ group experienced severe adverse events (scleritis and foreign body requiring surgery) in the fellow treated eyes, though these side effects were considered unrelated to treatment. Nonocular adverse events were experienced by $12.7 \%$ of subjects in the LBN $0.024 \%$ and $14.1 \%$ of subjects in the timolol $0.5 \%$ group. Treatment-related nonocular side effects were reported by $1.8 \%$ of subjects in the LBN $0.024 \%$ group and $2.2 \%$ of subjects in the timolol $0.5 \%$ group. In the LBN $0.024 \%$ group, these nonocular adverse events included headache, fatigue, sinus congestion, hair color changes, and hair disorder, and in the timolol $0.5 \%$ group, these included bradycardia, prodromal headache, and rhinorrhea. ${ }^{10}$

Both LBN and timolol were well tolerated by subjects in the LUNAR study, though more patients in the latanoprostene group experienced at least one ocular treatment-emergent adverse event $(23.8 \%$ of patients as compared to $13.3 \%$ of patients treated with timolol). Conjunctival hyperemia, eye irritation, and eye pain were the most frequently reported ocular adverse events in the LBN-treated eyes and, with the exception of one patient with severe conjunctival hyperemia, the severity of the remainder of the ocular side effects were considered mild or moderate. About $12.9 \%$ of individuals (36 of 278) treated with LBN and 13.2\% (18 of 136) of patients treated with timolol experienced nonocular adverse events, most of which were considered unrelated to topical therapy. Six events in five patients in the LBN group were considered potentially related to the drug (madarosis, chest discomfort, dysgeusia, headache, insomnia, and dyspnea), and four events in two patients in the timolol group were considered potentially related to the drug (headache $\times 2$, dizziness, and somnolence). ${ }^{26}$ In the pooled analysis of the APOLLO and LUNAR studies, the safety profile of LBN was found to be comparable to that of the prostaglandin analogs with conjunctival hyperemia being the most commonly reported adverse event. ${ }^{19}$

The JUPITER study evaluated the long-term safety of LBN $0.024 \%$ in the management of OAG and OHT. To date, this has been the longest study of LBN $0.024 \%$, with subjects followed for 52 weeks. One hundred thirty subjects were enrolled in the study. Overall, 76/130 (58.5\%) study eyes and $78 / 126$ (61.9\%) fellow eyes experienced $\geq 1$ ocular TEAE, all of which were deemed mild to moderate in severity. The most common TEAEs in both study and treated fellow eyes were conjunctival hyperemia (17.7\% and $16.7 \%$, respectively), eyelash growth (16.2\% and $16.7 \%$, respectively), eye irritation $(11.5 \%$ and $11.9 \%$, respectively), and eye pain $(10.0 \%$ and $10.3 \%$, respectively). Thirteen of 130 study eyes (10\%) and $11 / 125$ treated fellow eyes $(8.8 \%)$ had a clear increase in iris pigmentation after 52 weeks of therapy as compared 
to baseline photographs with $14.6 \%$ of study eyes and $13.6 \%$ of treated fellow eyes having a possible increase in iris pigmentation from baseline. Sixty-seven (51.5\%) individuals experienced at least one nonocular TEAE, none of which were considered related to the study drug. Four individuals discontinued the study due to TEAEs, none of which were considered related to LBN therapy. ${ }^{21}$

\section{Patient-focused perspectives}

Glaucoma remains a leading cause of blindness in the United States and around the world despite an increasing number of effective therapies. ${ }^{27}$ Even with the existence of effective treatments, surveyed patients believe that people with glaucoma will continue to lose vision. ${ }^{28}$ Patients with vision loss from glaucoma report worse quality of life with a trend of poorer quality of life with increasing disease severity. ${ }^{29} \mathrm{The}$ Glaucoma Quality of Life questionnaire has been developed to quantitatively assess glaucoma patients' quality of life and has been shown to correlate well with objective measures of visual function..$^{21,30}$

There are many barriers to glaucoma medication adherence. ${ }^{31-33}$ A recent cross-sectional survey published in Ophthalmology evaluated the frequency of eleven commonly cited barriers to optimal glaucoma medication adherence among glaucoma patients. Barriers that were assessed in the study included the following: difficulty with drop administration, poor self-efficacy, poor knowledge, beliefs about glaucoma, beliefs about medications, life stress, forgetfulness, side effects, cost, difficulty with medication schedules, and mistrust of the physician. Each of these eleven barriers was found to be important to at least $30 \%$ of surveyed patients with poor adherence and at least $23 \%$ of surveyed patients with good adherence. ${ }^{34}$ Given that many of these barriers relate to treatment concerns, it remains important that prescribed therapies are easy to administer, tolerable and halt glaucomatous damage without worsening a patient's quality of life.

The ease of once-daily administration of LBN combined with its potent IOP-lowering effect may improve patient adherence and compliance. In studies of latanoprost, reduction of IOP starts about 3-4 hours after drop administration and the maximum effect is reached after $8-12$ hours. ${ }^{35}$ Previous prospective, multicenter controlled trials in which qualified patients had previous glaucoma therapy substituted with latanoprost $0.005 \%$ resulted in reduced IOP, limited side effects and improvement in quality of life, and these benefits were maintained during both a 3- and 6-month trial. ${ }^{36,37}$ Though a comparable study has not (yet) been done with
LBN, we could hypothesize that the same results may also be found since LBN is made up of latanoprost acid (and butanediol mononitrate). The VOYAGER study, which compared latanoprost $0.005 \%$ to LBN $0.024 \%$ showed that subjects treated with LBN $0.024 \%$ had lower IOP than those treated with latanoprost $0.005 \%$ at days 7,14 , and $28,{ }^{17}$ suggesting the potential potent effects of LBN $0.024 \%$ as monotherapy, even over latanoprost.

LBN has been relatively well tolerated in all clinical trials, with very few study discontinuations. Only $4 / 121$ patients $(3.3 \%)$ in the JUPITER study (the longest study of LBN to date) discontinued treatment due to adverse events. ${ }^{20}$ However, multiple TEAEs have been shown in all published studies, with ocular and conjunctival hyperemia being among the most common. It is well known that hyperemia is a significant cause of patient noncompliance ${ }^{38}$ and thus it is possible that hyperemia would be a potential reason for patients to discontinue therapy with LBN in the real-world setting, outside of clinical trials.

Though some early studies of prostaglandin analogs showed pupil constriction after drop usage in humans ${ }^{39}$ and glaucomatous Beagles, ${ }^{40}$ potentially prompting recommendations for evening administration, other studies have not confirmed this finding. ${ }^{41-43} \mathrm{AM}$ dosing of eye drops has been shown to be associated with improved adherence in some patient populations, ${ }^{44}$ and all published studies of LBN to date have been done with evening dosing. It is unknown whether the same IOP-lowering effects of LBN would be seen with AM dosing and studies comparing AM vs PM administration of LBN may be warranted in the future.

Finally, cost is a critical factor in patient compliance with prescribed treatment regimens and cost has been shown to be a significant barrier to adherence. ${ }^{45,46}$ Branded medications are expensive and oftentimes cost prohibitive for patients. Patients are often on multiple eye drops, and each additional drop can add significant cost to the patient. Despite the potential benefits of LBN over other glaucoma therapies, if a patient cannot afford to purchase the medication, he will not use it. The pricing of LBN and whether or not insurance companies will cover it will be significant factors in the use of this drop by patients and in the prescribing patterns of ophthalmologists.

\section{Conclusion}

LBN has been shown to be an effective, safe, and welltolerated medication for patients with OAG and OHT. A modified prostaglandin analog, LBN is a novel nitric oxide-donating prostaglandin $F 2 \alpha$ analog that works to lower 
IOP by targeting both nitric oxide relaxation of the trabecular meshwork in conjunction with increased outflow through the uveoscleral pathway.

Dosed once daily in the post-meridiem, LBN has been shown in clinical trials to lower IOP to a greater effect than both timolol $0.5 \%$ and latanoprost $0.005 \%$. LBN $0.024 \%$ was found to be the lowest concentration of medication to achieve the largest reduction in IOP as compared to latanoprost $0.005 \%$. Diurnal and nocturnal studies have confirmed that IOP remains consistently reduced from baseline throughout the entire 24-hour period when a single drop of LBN is instilled nightly. This statistically significant increase in IOP lowering was found to be sustained for at least 1 year when studied in Japanese subjects, many of whom had normal tension glaucoma.

The side-effect profile of LBN is relatively mild in studies to date, and the medication has been well tolerated with very few study discontinuations. The most commonly reported TEAEs include conjunctival and ocular hyperemia, instillation site pain, eye pain and eye irritation, punctate keratitis, and eyelash growth. The easier, once daily dosing regimen has the potential to improve patient compliance with treatment.

LBN $0.024 \%$ is a promising new medication recently approved by the FDA for the treatment of OAG and OHT. This medication has the potential to be used as a first-line therapy for patients to reduce IOP, decrease risk of glaucoma progression, and preserve vision while maintaining patients' quality of life.

\section{Disclosure}

The authors report no conflicts of interest in this work.

\section{References}

1. Friedman DS, Wolfs RC, O'Colmain BJ, et al. Prevalence of openangle glaucoma among adults in the United States. Arch Ophthalmol. 2004;122(4):532-538.

2. Varma R, Lee PP, Goldberg I, Kotak S. An assessment of the health and economic burdens of glaucoma. Am J Ophthalmol. 2011;152(4): $515-522$.

3. Weinreb RN, Khaw PT. Primary open-angle glaucoma. Lancet. 2004; 363(9422):1711-1720.

4. Heijl A, Leske MC, Bengtsson B, et al. Reduction of intraocular pressure and glaucoma progression: results from the Early Manifest Glaucoma Trial. Arch Ophthalmol. 2002;120(10):1268-1279.

5. Leske MC, Heijl A, Hyman L, Bengtsson B, Komaroff E. Factors for progression and glaucoma treatment: the Early Manifest Glaucoma Trial. Curr Opin Ophthalmol. 2004;15(2):102-106.

6. Chauhan BC, Mikelberg FS, Balaszi AG, et al. Canadian Glaucoma Study: 2. risk factors for the progression of open-angle glaucoma. Arch Ophthalmol. 2008;126(8):1030-1036.

7. Fishman P, Cohen S, Bar-Yehuda S. Targeting the A3 adenosine receptor for glaucoma treatment (review). Mol Med Rep. 2013;7(6): $1723-1725$.
8. Kaufman MB. Pharmaceutical approval update. PT. 2018;43(1): $22-60$.

9. Kaufman PL. Latanoprostene bunod ophthalmic solution $0.024 \%$ for IOP lowering in glaucoma and ocular hypertension. Expert Opin Pharmacother. 2017;18(4):433-444.

10. Hoy SM. Latanoprostene bunod ophthalmic solution $0.024 \%$ : a review in open-angle glaucoma and ocular hypertension. Drugs. 2018;78(7):773-780.

11. Lu LJ, Tsai JC, Liu J, Lj L, Lui J. Novel pharmacologic candidates for treatment of primary open-angle glaucoma. Yale J Biol Med. 2017;90(1): $111-118$.

12. Lindsey JD, Kashiwagi K, Kashiwagi F, Weinreb RN. Prostaglandins alter extracellular matrix adjacent to human ciliary muscle cells in vitro. Invest Ophthalmol Vis Sci. 1997;38(11):2214-2223.

13. Cavet ME, Vittitow JL, Impagnatiello F, Ongini E, Bastia E. Nitric oxide (NO): an emerging target for the treatment of glaucoma. Invest Ophthalmol Vis Sci. 2014;55(8):5005-5015.

14. Cavet ME, Decory HH. The role of nitric oxide in the intraocular pressure lowering efficacy of latanoprostene bunod: review of nonclinical studies. J Ocul Pharmacol Ther. 2018;34(1-2):52-60.

15. Saeki T, Tsuruga H, Aihara M, Araie M, Rittenhouse K. Dose-response profile of PF-03187207 (PF-207) and peak IOP lowering response following single topical administration to FP receptor knockout mice versus wild type mice. Invest Ophthalmol Vis Sci. 2009;50(4064).

16. Araie M, Sforzolini BS, Vittitow J, Weinreb RN. Evaluation of the effect of latanoprostene bunod ophthalmic solution, $0.024 \%$ in lowering intraocular pressure over $24 \mathrm{~h}$ in healthy Japanese subjects. Adv Ther. 2015;32(11):1128-1139.

17. Eveleth D, Starita C, Tressler C. A 4-week, dose-ranging study comparing the efficacy, safety and tolerability of latanoprost 75,100 and $125 \mu \mathrm{g} / \mathrm{mL}$ to latanoprost $50 \mu \mathrm{g} / \mathrm{mL}$ (xalatan) in the treatment of primary open-angle glaucoma and ocular hypertension. BMC Ophthalmol. 2012;12:9.

18. Weinreb RN, Ong T, Scassellati Sforzolini B, et al. A randomised, controlled comparison of latanoprostene bunod and latanoprost $0.005 \%$ in the treatment of ocular hypertension and open angle glaucoma: the VOYAGER study. Br J Ophthalmol. 2015;99(6):738-745.

19. Liu JHK, Slight JR, Vittitow JL, Scassellati Sforzolini B, Weinreb RN. Efficacy of Latanoprostene bunod $0.024 \%$ compared with Timolol $0.5 \%$ in lowering intraocular pressure over 24 hours. Am J Ophthalmol. 2016;169:249-257.

20. Weinreb RN, Liebmann JM, Martin KR, Kaufman PL, Vittitow JL. Latanoprostene bunod $0.024 \%$ in subjects with open-angle glaucoma or ocular hypertension: pooled phase 3 study findings. J Glaucoma. 2018; 27(1):7-15.

21. Kawase K, Vittitow JL, Weinreb RN, Araie M; JUPITER Study Group. Long-term safety and efficacy of latanoprostene bunod $0.024 \%$ in Japanese subjects with open-angle glaucoma or ocular hypertension: the JUPITER Study. Adv Ther. 2016;33(9):1612-1627.

22. Cantisani C, Ambrifi M, Frascani F, et al. Glaucoma eye drops adverse skin reactions. Recent Pat Inflamm Allergy Drug Discov. 2014;8(3): 192-195.

23. Aguayo Bonniard A, Yeung JY, Chan CC, Birt CM. Ocular surface toxicity from glaucoma topical medications and associated preservatives such as benzalkonium chloride (BAK). Expert Opin Drug Metab Toxicol. 2016;18:1279-1289.

24. Uusitalo H, Egorov E, Kaarniranta K, Astakhov Y, Ropo A. Benefits of switching from latanoprost to preservative-free tafluprost eye drops: a meta-analysis of two Phase IIIb clinical trials. Clin Ophthalmol. 2016; 10:445-454.

25. Thygesen J. Glaucoma therapy: preservative-free for all? Clin Ophthalmol. 2018;12:707-717.

26. Medeiros FA, Martin KR, Peace J, Scassellati Sforzolini B, Vittitow JL, Weinreb RN. Comparison of Latanoprostene bunod $0.024 \%$ and Timolol maleate $0.5 \%$ in open-angle glaucoma or ocular hypertension: the LUNAR study. Am J Ophthalmol. 2016;168:250-259. 
27. Quigley HA, Broman AT. The number of people with glaucoma worldwide in 2010 and 2020. Br J Ophthalmol. 2006;90(3):262-267.

28. Newman-Casey PA, Shtein RM, Coleman AL, Herndon L, Lee PP. Why patients with glaucoma lose vision: the patient perspective. J Glaucoma. 2016;25(7):e668-e675.

29. Nelson P, Aspinall P, Papasouliotis O, Worton B, O’Brien C. Quality of life in glaucoma and its relationship with visual function. J Glaucoma. 2003;12(2):139-150.

30. Goldberg I, Clement CI, Chiang TH, et al. Assessing quality of life in patients with glaucoma using the Glaucoma Quality of Life-15 (GQL-15) questionnaire. J Glaucoma. 2009;18(1):6-12.

31. Lacey J, Cate H, Broadway DC. Barriers to adherence with glaucoma medications: a qualitative research study. Eye. 2009;23(4):924-932.

32. Stryker JE, Beck AD, Primo SA, et al. An exploratory study of factors influencing glaucoma treatment adherence. J Glaucoma. 2010;19(1): 66-72.

33. Tsai JC, Mcclure CA, Ramos SE, Schlundt DG, Pichert JW. Compliance barriers in glaucoma: a systematic classification. J Glaucoma. 2003; 12(5):393-398.

34. Newman-Casey PA, Robin AL, Blachley T, et al. The most common barriers to glaucoma medication adherence: a cross-sectional survey. Ophthalmology. 2015;122(7):1308-1316.

35. Summary of Product Characteristics. Xalatan 50 micrograms $/ \mathrm{ml}$ Eye Drops Solution. Pfizer Limited. Updated. Available from: https://www. medicines.org.uk/emc/product/1616/smpc

36. Haverkamp F, Wuensch S, Fuchs M, Stewart WC. Intraocular pressure, safety and quality of life in glaucoma patients switching to latanoprost from adjunctive and monotherapy treatments. Eur J Ophthalmol. 2004; 14(5):407-415.

37. Zimmerman TJ, Stewart WC; Latanoprost Axis Study Group. Intraocular pressure, safety, and quality of life in glaucoma patients switching to latanoprost from monotherapy treatments. J Ocul Pharmacol Ther. 2003;19(5):405-415.
38. Feldman RM. Conjunctival hyperemia and the use of topical prostaglandins in glaucoma and ocular hypertension. J Ocul Pharmacol Ther. 2003;19(1):23-35.

39. Dinslage S, Diestelhorst M, Kühner H, Krieglstein GK. The effect of latanoprost $0.005 \%$ on pupillary reaction of the human eye. Ophthalmologe. 2000;97(6):396-401.

40. Gelatt KN, Mackay EO. Effect of different dose schedules of latanoprost on intraocular pressure and pupil size in the glaucomatous Beagle. Vet Ophthalmol. 2001;4(4):283-288.

41. Marchini G, Ghilotti G, Bonadimani M, Babighian S. Effects of $0.005 \%$ latanoprost on ocular anterior structures and ciliary body thickness. J Glaucoma. 2003;12(4):295-300.

42. Zarnowski T, Kawa P, Jurkowska-Dudzińska J, Zagórski Z. Clinical evaluation of isopropyl unoprostone (Rescula), in the adjunctive treatment of primary open angle glaucoma. Klin Oczna. 2001;103(1): $13-15$.

43. Ba-Ali S, Sander B, Brøndsted AE, Lund-Andersen H. Effect of topical anti-glaucoma medications on late pupillary light reflex, as evaluated by pupillometry. Front Neurol. 2015;6:93.

44. Ford BA, Gooi M, Carlsson A, Crichton AC. Morning dosing of oncedaily glaucoma medication is more convenient and may lead to greater adherence than evening dosing. J Glaucoma. 2013;22(1):1-4.

45. Sleath B, Robin AL, Covert D, Byrd JE, Tudor G, Svarstad B. Patientreported behavior and problems in using glaucoma medications. Ophthalmology. 2006;113(3):431-436.

46. Friedman DS, Hahn SR, Gelb L, et al. Doctor-patient communication, health-related beliefs, and adherence in glaucoma results from the Glaucoma Adherence and Persistency Study. Ophthalmology. 2008;115(8): $1320-1327$.
Clinical Ophthalmology

\section{Publish your work in this journal}

Clinical Ophthalmology is an international, peer-reviewed journal covering all subspecialties within ophthalmology. Key topics include: Optometry; Visual science; Pharmacology and drug therapy in eye diseases; Basic Sciences; Primary and Secondary eye care; Patient Safety and Quality of Care Improvements. This journal is indexed on

\section{Dovepress}

PubMed Central and CAS, and is the official journal of The Society of Clinical Ophthalmology (SCO). The manuscript management system is completely online and includes a very quick and fair peer-review system, which is all easy to use. Visit http://www.dovepress.com/ testimonials.php to read real quotes from published authors. 